\title{
BUILDING A POTENTIAL TO COUNTERACT HYBRID THREATS THROUGH COOPERATION AND REGIONAL SECURITY
}

\author{
Vice Admiral Emil EFTIMOV
}

\begin{abstract}
The main goal of this article is to present and discuss the opportunities to deepen cooperation between the Alliance and partners in countering hybrid threats. The focus is put on the eastern and southern NATO flanks, where the most advanced partner formats like Partnership for Peace (PfP) and Mediterranean Dialog (MD) have been developed. The first conclusion is that NATO partnership programs and the various initiatives in the interest of the partners are aimed at achieving stability in the periphery of the Alliance by increasing partners' resilience to various types of threats. In addition, the author argues that success in countering hybrid threats in the current security environment is impossible without parallel and coordinated action of NATO in coordination with other international organizations, especially the European Union.
\end{abstract}

Keywords: NATO, EU, Partnership for Peace, Mediterranean Dialogue, hybrid threats, resilience, international military cooperation.

\section{Introduction}

The strategy on NATO role in countering the hybrid type of war states that the first reaction or response comes from the nation under threat / attack, and the member states of NATO should build a set of capabilities and countermeasures. Also, there is a provision for the possibility of help or assistance by organizations whose members or partners these states are. In this case, the fundamental role of NATO in supporting the member states and partners is in the military aspect. The abovementioned strategy sets out the conditions and prerequisites for success, stressing on the need for building policies, mechanisms, and capacities for maintaining the following three interrelated functions: PREPARE, DETER and DEFEND.

The DETER and DEFEND functions are in the core of the Readiness Action Plan adopted in 2014 in Wales, and in its detailed NATO Graduated Response Plans being a main military instrument in situations of hybrid threats or hybrid warfare. 
The NATO defence ministers adopted a plan to implement the strategy on NATO role in countering hybrid warfare, which addresses mostly the abovementioned PREPARE function. The plan provides an overview at strategic level of what needs to be done to get the North Atlantic Treaty Organization ready. In short, the plan deals with building skills to detect and categorize (attribute) hybrid activity; also, rapid assessment, analysis and effective decision-making process, as well as building resilience, response and counteraction to hybrid campaigns.

The plan is a tool for coordination and review of achievements, but it also serves for identifying mistakes and for future planning. The PREPARE function emphasizes on the fact that the resulting tasks are not only specific to NATO internal dimensions aimed at organizational change and proactive model of work and external, but also to external ones. The external dimensions include the need for a more effective cooperation and coordination with partner states and the relevant international organizations, especially with the EU, as a key element in combating hybrid campaigns.

I will not dwell on NATO Strategic Concept, adopted in 2011, which outlines the principles of relations with NATO partner countries. Despite the changes in the security environment, these principles are still valid today. But speaking to a military audience, I have to mention the direct contribution of our partners in NATO-led operations. Even in today's situation, a brief look at Afghanistan shows that not counting the US contingent in Resolute Support Operation, the number of troops of the partners is equal to the contribution of all the other 27 NATO countries, except for the US. In other words, without their contribution, we would have to double ours with all the consequent resource and political ramifications. I leave the possible consequences without comment.

Analysing the security environment with the presence of a hybrid threat from the eastern and southern NATO flank, where we have the most advanced partner formats (PfP, MD), we can recognize the following realities:

- The NATO partner countries, facing a growing threat require support and assistance adapted to current conditions.

- For a better and more effective provision for DETER and DEFENSE functions, NATO should seek to promote and maintain security and stability in the regions and countries adjacent to the Alliance.

NATO adaptation to the changing security environment was initiated in Wales, and alongside with the Action Readiness Plan, specific initiatives were announced aiming at facing the abovementioned realities, and significantly adapting our approach to the partners. Through these initiatives we show that we do not try solely to increase our 
own collective security, but we remain bound to them, and together we confront the challenges to the Euro-Atlantic Community. Now, a few words about these initiatives:

Defence Capacity Building Initiative. It includes methodological backup, advice and support, training and monitoring in the security sector and defence. The mechanism is to be triggered at the request of a partner country. It addresses specific needs and is additional with respect to the existing partner programs, mechanisms and implements. It is interesting to note that beneficiaries can also be third parties who are not NATO partners, the program can be applied "in a hostile environment" in the so-called nonpermissive environment. The initially discussed potential beneficiaries were Ukraine, Georgia, Moldova, Tunisia, Libya, Iraq and Jordan; and Georgia, Jordan, Iraq, Moldova and Libya were announced at the NATO summit in September 2014, when the local conditions permitted.

I'll briefly describe the current content of the existing packages for these countries.

First, Partnership Interoperability Initiative. You may ask why, given that the involvement of partners in NATO-led operations is reported as a success. The answer lies precisely in how to maintain the achieved and costly level of interoperability provided that by 2014 NATO has significantly reduced the volume of operations. The way is through advanced plans and programs for individual and collective training, access to early planning and participation in exercises and adapted financial support and subsidies. Partner countries in this initiative were selected according to specific criteria such as participation in: NATO operations, NATO response forces, the interoperability concept, NATO exercises; and, also, keeping personnel in the NATO command structure. Currently, it covers 25 countries, and the status is valid for two years.

Let me now briefly describe the highlights of our partnership with some of the partners who are facing serious challenges.

\section{Ukraine}

I'll begin with Ukraine, having in mind the contemporary manifestation of hybrid warfare which in many publications and studies is claimed to be nothing new as a phenomenon, but rather a modern way of implementation. Essentially, my opinion is that a country facing a particular situation turns out to be paralyzed with respect of political decision-making systems, lacks adequate systems for security, defence, command and control, and situational awareness. Before February 2014, Ukraine claimed almost privileged status in NATO, citing his participation in all NATO operations, including OSEAN SHIELD at the time. The focus of our military cooperation fell on interoperability rather than building abilities, for which the government claimed to 
have effective procedures. Following the situation developments, in September 2014 NATO established five trust funds, including resources and expertise to:

- Command, control, communications and computers to modernize the command and control systems.

- Logistics and standardization in order to complete the reform of the logistics system

- Cyber defence in order to build technical capabilities to counter cyber threats.

- Reintegration of military personnel / Military Career Management Trust Fund

- Medical recovery and rehabilitation.

At the initiative of NATO Military Committee, a sixth fund was created - Explosive Ordnance Disposal. It is worth noting also the increased activity in programs like: science for peace and security, integrity building, professional development support, and support for reforms in the military education where the Bulgarian participation is significant. The annual plan for military cooperation follows the trend for capacity building, military budget assistance for education, training, drills and exercises, as well as development of concepts and doctrines.

My personal impression is that after the initial inevitable confusion and chaos, now there is a desire to build real skills tailored to the demographic and economic potential of the country. A huge contribution to this process comes from the support based on bilateral relations, international organizations and institutions, and political and expert assistance from NATO. On the other hand, the experience and the lessons that can be learned by studying the events in the country are enormous. I participated in a workshop on lessons learned from the operation in eastern Ukraine, and I think there is useful information for the use of armoured vehicles, artillery, unmanned aerial vehicles, Special Forces and others in modern conditions.

\section{Georgia}

There are two main points that characterize in short the complexity of NATO - Georgia relations. The first is the desire of Georgia to guarantee the sovereignty and territorial integrity being a NATO member. For this reason, its so-called MAP (Membership Action Plan) can be activated. The second point is the wait-and-see policy of NATO, despite the enormous contribution of Georgia to NATO-led operations. Currently, 12,000 Georgians have participated in ISAF, with 28 casualties, more than 300 injured, 60 of them with permanent disability, 870 people contingent in RSM Operation without national restrictions. Instead of the so much desired MAP, at the 
summit in Wales, Georgia was proposed a so-called Substantial Package (SNGP). The idea is, through targeted technical assistance and financing, improvement of the functioning of the security and defence systems, and increase of the interoperability with allies and partners. NATO countries are involved in the following areas:

- Providing support and assistance in strategic and operational planning;

- Special Forces;

- Cyber protection and defence;

- Improving the exchange of intelligence information and secured communications;

- Joint Education and Training Centre with the main idea to promote transformation in Armed Forces through education, training, exercises and assessment. National, regional and NATO exercises are considered;

- Acquisition of defence products;

- Aviation;

- Air Defence;

- Maritime sovereignty;

- Centre for qualification in building defence institutions;

- Construction of logistics elements;

- Military Police;

- Strategic communications.

NATO support, expanded and extended on the basis of bilateral cooperation, has a significant contribution to enhancing the capabilities of the Georgian Armed Forces. I think it will not be long until Georgia declares that it is military ready for membership and expects a political decision.

\section{Moldova}

The package to build adequate capabilities in Moldova was approved in June 2015, and provides initial modernization of the national security strategy with subsequent development of defence and military strategy. The next step is determining the appropriate force structure and the necessary capabilities. This first phase largely depends on the political will of the MoD and the political developments. The second phase provides technical assistance in the development of the Land Forces and the Air Force command and control, doctrine, military education, infrastructure, defence and so on. A decision has been made for opening a NATO office in Chisinau. 
Dear colleagues, this completes my tour to the East and I move on to South. It is universally accepted that the potential threat from the East is characterized by significant military capabilities and the situation in the South - not only by its unpredictability, but also by the urgency of finding an adequate response. At a meeting in January 2016, the Chiefs of Defence of NATO countries clearly expressed their views on the so-called Military Prospects for the future NATO strategy, positioning, and adjustment. According to them, the activities of the NATO military structures within the three main strategic tasks should be directed to the efficient work of the following functions: DETER, CONTAIN, PROTECT and PROJECT STABILITY. With regard to the direction of South, the focus is on CONTAIN functions in order to curb the radical Islam, and PROJECT in order to contribute to stability in the region with proactive actions in support of one of the NATO main tasks - Security Through Cooperation. Based also on the condition that the main objective of The Defence and Related Security Capacity Building (DCB) Initiative is building stability without significant deployment of military units, the current NATO activities in addition to partnership programs are as follows:

\section{Jordan}

The Specialized Assistance Package to Jordan was approved in November 2014 and includes areas such as: data protection, cyber defence, military exercises, combating improvised explosive devices, communications, command and control, protection of harbours and border security. Considering the progress in these areas mostly through education, training and exercises, Jordan has intensified requests for material assistance, especially in terms of border security. The country has deployed three brigades of ground infrastructure and monitoring systems on its borders with Syria and Iraq.

\section{Iraq}

After long negotiations (until a government is formed) in July 2015, NATO and Iraq have agreed to additional help in fight against improvised explosive devices, ammunition, military medicine, advice and assistance in the security sector, cyber defence, civil-military planning in the preparation of operations, Civil emergency planning and readiness and military education and training. The main objective now is to start training Iraqis in Jordan in March 2016 on combating improvised explosive devices, military medicine, and civil-military planning.

\section{Libya}

NATO - Libya dialogue has existed since May 2013 when the then prime minister of Libya requested NATO assistance for establishment of the National Guard in order to reintegrate the revolutionary brigades. Subsequently, their concept of National Guard 
failed and they asked for help to build a national architecture in the sectors of security and defence. NATO gave a positive response in October 2013. By this time, due to the negative developments in the security environment and the lack of consensus, despite the fact that a National Political Agreement was signed on December 17, 2016, NATO holds its position from September 2014. Provided that a government of national consent is formed, except for the above-mentioned areas, the possible role of NATO in coordination and supplement of the UN, the EU, and the presented by the Italian MoD possible Libyan International Assistance Mission (LIAM) could be rendered into:

- Comprehensive support and assistance in construction of National Guard;

- In addition to the help in institution-building in the security sector, NATO could support a possible Libya International Assistance Mission in the following areas:

1. Situational awareness and information exchange;

2. AWACS support Airborne Warning and Control System;

3. Maritime Information Awareness. As part of the development of marine positioning of the Alliance, opportunities should be searched for coordinating and reaching complete information about the situation at sea and exchange of information. In particular, this can be achieved alongside with EC EUNAVFORMED / SOFIA operation, including monitoring and reporting the illegal traffic to and from Libya;

4. Strategic LIAM air transport to and from Libya.

All of this is real and achievable, but naturally, it is in the field of possible options, and requires further analysis and planning if necessary. Let me emphasize that these actions are only possible if there is a request from the Government of Libya or is based on a resolution of the United Nations Security Council.

The foregoing is to the constant attention of the NATO Military Authorities, and what we offer for operationalizing The Defence and Related Security Capacity Building (DCB) Initiative is to strengthen following at political level:

- Expanding the scope of consultation, advice and support to provide material support and greater use of partner implements

- Creating a coalition of willing countries and a Framework Nation for each beneficiary of DCB and attracting partner and non-partner countries. The Framework Nation is to have the power to coordinate with international organizations, including EU.

- Clear delineation of responsibilities, and the packages implementation to be more closely connected with NATO Rapid Reaction Corps. 
- Expansion of the beneficiary countries, such as Tunisia.

- Defining the packages according to the security environment in the beneficiary country. In such favourable DCB, the activity is to be in addition to affiliate programs; in case of unfavourable one, the processes and procedures used during NATO operations and missions are to be followed.

- Financing. According to the definition, DCB activity is mainly on the budget of affiliate programs, trust funds and voluntary sponsorship of NATO member states, which turns out not to be enough. Another way is recommended to be found - target funding from the general budget.

The implementation of these recommendations would be ineffective in the absence of policy or strategy to address the security challenges in this region which so important to European security.

Returning to the definition of hybrid threat, it is clear from the foregoing that NATO partnership programs and the various initiatives in the interest of the partners are aimed at achieving stability in the periphery of NATO by increasing their resilience to various types of threats. Success in the contemporary circumstances is impossible without parallel and coordinated action with other international organizations, especially the EU. In the hybrid context, it is worth noting the "Joint Framework for Combating Hybrid Threats - response of the European Union" adopted in April 2016. The document provides for the exchange of information between NATO and the EU concerning cyber / hybrid attacks, which is a good prerequisite for future joint actions.

\section{About the Author}

Vice Admiral Emil Eftimov has been Deputy Chief of Defence of the Republic of Bulgaria since March 2017. He graduated from "Nikola Vaptsarov" Naval Academy, Varna in 1984, "N.G.Kuznetsov" Naval Academy, Saint Petersburg, Russia in 1994 and U.S. Naval War College, Newport, Rhode Island in. 2005. In addition, VA Eftimov attended Senior Officers Course, NATO School Oberammergau, Germany and Flag Officers and Ambassadors Course, NATO Defence College, Rome, Italy in 2012. His military career started as Navigation Officer, Frigate Class Ship in Varna Naval Base. After having served on various positions in the Navy, he became the Commander of Varna Naval Base. From 2011 to 2013 VA Eftimov was Deputy Director of Cooperation and Regional Security Division, International Military Staff, NATO HQ, Brussels and from 2013 to 2016 - Director of the same Division. 